\title{
INCREASING RETURNS AND UNSYNCHRONIZED WAGE ADJUSTMENT IN SUNSPOT Models OF THE BuSINESS CyCLE
}

\section{by}

Kevin X.D. Huang and Qinglai Meng

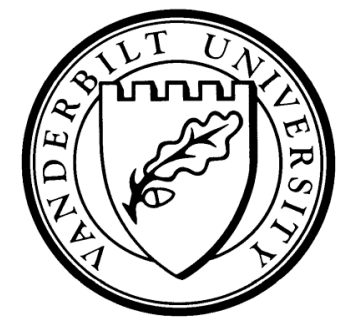

Working Paper No. 10-W07

March 2010

\section{DEPARTMENT OF ECONOMICS \\ VANDERBILT UNIVERSITY \\ NASHVILLE, TN 37235}

www.vanderbilt.edu/econ 


\title{
Increasing Returns and Unsynchronized Wage Adjustment in Sunspot Models of the Business Cycle
}

\author{
Kevin X.D. Huang ${ }^{\mathrm{a}, *}$, Qinglai Meng ${ }^{\mathrm{b}, \mathrm{c}}$ \\ ${ }^{a}$ Department of Economics, Vanderbilt University, Nashville, TN 37235, USA \\ ${ }^{b}$ Department of Economics, Oregon State University, Corvallis, OR 97330, USA \\ ${ }^{c}$ Department of Economics, Chinese University of Hong Kong, Shatin, N.T., Hong Kong
}

\begin{abstract}
A challenge facing the literature of equilibrium indeterminacy and sunspot-driven business cycle fluctuations based on increasing returns to scale in production is that the required degree of increasing returns for generating indeterminacy can be implausibly large and rise quickly with the relative risk aversion in labor. We show that unsynchronized wage adjustment via a relative wage effect can both lower the required degree of increasing returns for indeterminacy to an empirically plausible level and make it invariant to the relative risk aversion in labor. As a result, indeterminacy and sunspot-driven business cycle fluctuations may emerge for empirically plausible increasing returns regardless of the value of the relative risk aversion in labor. The impulse responses of our model to demand shocks under indeterminacy are reasonable in terms of matching the business cycle, and sunspot shocks become more important due to the presence of labor market frictions.
\end{abstract}

JEL classification: E12; E31; E52

Keywords: Increasing returns; Unsynchronized wage adjustment; Relative wages; Relative risk aversion in labor; Indeterminacy; Sunspot

\footnotetext{
${ }^{*}$ Corresponding author. Department of Economics, Vanderbilt University, VU Station B 351819, 2301 Vanderbilt Place, Nashville, TN 37235-1819, USA. Tel.: +1 615936 7271; fax: +1 6153438495.

E-mail address: kevin.huang@vanderbilt.edu (K.X.D. Huang).
} 


\section{INTRODUCTION}

It has long been argued that economies of scale can be a potential source of sunspot-driven business cycle fluctuations (e.g., Benhabib and Farmer, 1994). In one-sector models with variable capacity utilization mild increasing returns to scale in production may generate an indeterminate equilibrium and sunspot-driven business cycles under the assumption of zero relative risk aversion in labor (e.g., Wen, 1998; Benhabib and Wen, 2004); but, even with a tiny relative risk aversion in labor the degree of increasing returns required for indeterminacy can be implausibly large, and it increases sharply with the relative risk aversion in labor. A similar problem also exists for twosector models (e.g., Benhabib and Farmer, 1996). This poses a challenge to the plausibility of sunspot-driven business cycle fluctuations based on increasing returns to scale in production.

One point of this paper is that unsynchronized wage adjustment via a relative wage effect can both lower the required degree of increasing returns for indeterminacy to an empirically plausible level and make it invariant to the relative risk aversion in labor. As a consequence, an indeterminate equilibrium and thus sunspot-driven business cycle fluctuations may emerge for empirically plausible increasing returns regardless of the value of the relative risk aversion in labor. We show that the impulse responses of the model to demand shocks under indeterminacy are reasonable in terms of matching the business cycle and sunspot shocks become more important due to the presence of labor market frictions.

In what follows, Section 2 sets up the model, Section 3 describes model calibration and reports

our indeterminacy results, Section 4 provides some intuition for the results, Section 5 presents the model's general solution and impulse responses to fundamental shocks under determinacy and to both fundamental shocks and sunspot shocks under indeterminacy, and Section 6 contains a brief concluding remark. Some of the technical detail can be found in the three appendices.

\section{A ONE-SECTOR MODEL OF MONOPOLISTIC COMPETITION}

We augment the Benhabib and Farmer's (1994) model of monopolistic competition in the goods market with variable capacity utilization in production, in the spirit of Greenwood, Hercowitz, and Huffman (1988), Wen (1998), and Benhabib and Wen (2004), and money in the utility function as 
an asset to provide liquidity services. We model monopolistic competition in the labor market also, which allows us to study the effect of unsynchronized wage adjustment in a standard way.

The economy consists of a continuum of households that are endowed with differentiated labor skills indexed by $i \in[0,1]$, and that set nominal wages for their services in a staggered fashion à là Calvo (1983) with a hazard rate $\theta$ of unable to adjusting wages at each given date, and a continuum of firms that produce differentiated intermediate goods indexed by $j \in[0,1]$, and that set nominal prices for their goods in a synchronized fashion. ${ }^{1}$ The production for each of the intermediate goods uses a composite labor $n_{t}=\left[\int_{0}^{1} n_{t}(i)^{(\epsilon-1) / \epsilon} d i\right]^{\epsilon /(\epsilon-1)}$, where $\epsilon>1$ measures the elasticity of substitution between the differentiated skills, and the final goods is composed from the intermediate goods according to $y_{t}=\left[\int_{0}^{1} y_{t}(j)^{1 / \varepsilon} d j\right]^{\varepsilon}$, where $\varepsilon>1$ measures the the monopolistic markup of price over marginal cost. The demand for a type $i$ labor is $n_{t}(i)=\left[W_{t}(i) / W_{t}\right]^{-\epsilon} n_{t}$, where the nominal wage rate $W_{t}$ for the composite skill and the nominal wage rates $\left\{W_{t}(i)\right\}_{i \in[0,1]}$ for the differentiated skills are linked by $W_{t}=\left[\int_{0}^{1} W_{t}(i)^{1-\epsilon} d i\right]^{1 /(1-\epsilon)}$. The demand for an intermediate good $j$ is given by $y_{t}(j)=\left[P_{t}(j) / P_{t}\right]^{\varepsilon /(1-\varepsilon)} y_{t}$, where the price $P_{t}$ for the final goods and the prices $\left\{P_{t}(j)\right\}_{j \in[0,1]}$ for the intermediate goods are linked by $P_{t}=\left[\int_{0}^{1} P_{t}(j)^{1 /(1-\varepsilon)} d j\right]^{1-\varepsilon}$.

At any given date $t$, a household $i$ seeks to maximize

$$
\mathrm{E}_{\mathrm{t}} \sum_{s=t}^{\infty} \rho^{s-t}\left[\log c_{t}(i)+\psi_{1} \log \frac{M_{t}(i)}{P_{t}}-\psi_{2} \frac{n_{t}(i)^{1+\chi}}{1+\chi}\right], \quad \text { for } \psi_{1}>0, \psi_{2}>0
$$

where $\mathrm{E}_{\mathrm{t}}$ is the conditional expectations operator, $\rho \in(0,1)$ is a subjective discount factor, $c_{t}(i)$ and $M_{t}(i)$ are consumption and nominal money balances, respectively, and $\chi \geq 0$ measures the relative risk aversion in labor, subject to

$\frac{M_{s}(i)}{P_{s}}=\frac{M_{s-1}(i)}{P_{s}}+\frac{W_{s}(i)}{P_{s}} n_{s}(i)+r_{s} u_{s}(i) k_{s}(i)-c_{s}(i)-\left\{k_{s+1}(i)-\left[1-\delta\left(u_{s}(i)\right)\right] k_{s}(i)\right\}+f_{s}(i)+\tau_{s}(i)$,

for $s \geq t$, where $k_{s}(i)$ is capital, $r_{s}$ is real capital rental rate, $f_{s}(i)$ and $\tau_{s}(i)$ are real profit and transfer from firms and the government, respectively, $u_{s}(i) \in(0,1)$ is capacity utilization rate, and the capital depreciation rate is an increasing and convex function of the capacity utilization rate, $\delta(u)=u^{\phi} / \phi, \phi>1$, as in Greenwood, Hercowitz, and Huffman (1988), Wen (1998), and Benhabib

\footnotetext{
${ }^{1}$ It turns out that unsynchronized price-setting has a negligible effect on the local stability property of the model, so we consider synchronized price-setting, as in Benhabib and Farmer (1994), to keep our analysis punchy.
} 
and Wen (2004). The household takes its initial capital and money holdings, and all rental rates and prices as given.

We assume that all households have identical initial endowments of capital and money stock. We follow the literature on staggered wage-setting to assume that there are (implicit) financial arrangements that make the households able to insure against idiosyncratic income risks that may arise from the unsynchronized wage adjustment so that their equilibrium consumption, investment, and capital utilization rate are identical, although their nominal wages and hours worked may differ (e.g., Rotemberg and Woodford, 1997; Erceg, Henderson, and Levin, 2000; Christiano, Eichenbaum, and Evans, 2005). The optimality conditions for utility maximization imply

$$
\begin{gathered}
W_{t}(i)=\left[\frac{\psi_{2} \epsilon}{\epsilon-1} \frac{\left.W_{t}^{(1+\chi) \epsilon} n_{t}^{1+\chi} P_{t}+\mathrm{E}_{\mathrm{t}} \sum_{s=t+1}^{\infty}(\theta \rho)^{s-t}\left(\prod_{h=1}^{s-t} \pi_{t+h}\right)^{-1} W_{s}^{(1+\chi) \epsilon} n_{s}^{1+\chi} P_{s}\right]_{t}^{\frac{1}{1+\chi \epsilon}},}{W_{t}^{-1}+\mathrm{E}_{\mathrm{t}} \sum_{s=t+1}^{\infty}(\theta \rho)^{s-t}\left(\prod_{h=1}^{s-t} \pi_{t+h}\right)^{-1} W_{s}^{\epsilon} n_{s} c_{s}^{-1}}\right. \\
\psi_{1} \frac{P_{t} c_{t}}{M_{t}}=1-\rho \mathrm{E}_{\mathrm{t}}\left(\frac{P_{t} c_{t}}{P_{t+1} c_{t+1}}\right), \\
1=\rho \mathrm{E}_{\mathrm{t}}\left\{\frac{c_{t}}{c_{t+1}}\left[1-\delta\left(u_{t+1}\right)+r_{t+1} u_{t+1}\right]\right\}
\end{gathered}
$$

where (11) is the optimal wage-setting equation, (2) comes from optimal capacity utilization choice, and (3) and (4) arise from optimal decisions for consumption and for money and capital holdings.

At any given date $t$, an intermediate goods $j$ is produced using capital and labor according to

$$
y_{t}(j)=\left\{\left[u_{t}(j) k_{t}(j)\right]^{\alpha} n_{t}(j)^{1-\alpha}\right\}^{\eta}, \quad \text { for } \alpha \in(0,1),
$$

where $\eta>1$ measures the degree of increasing returns to scale at the individual firm level. It is worth noting that the profit maximization problem for each individual firm has an interior solution provided the degree of increasing returns to scale $\eta$ is bounded above by the monopolistic markup $\varepsilon$. It can be shown that aggregate quantities are linked to real factor prices by

$$
w_{t}=\frac{(1-\alpha) \eta y_{t}}{\varepsilon n_{t}}, \quad r_{t}=\frac{\alpha \eta y_{t}}{\varepsilon u_{t} k_{t}}
$$

where $w_{t}$ is real wage rate for the composite labor, $k_{t}=\int_{0}^{1} k_{t}(i) d i=\int_{0}^{1} k_{t}(j) d j$, and aggregate 
production function has the reduced form $y_{t}=\left[\left(u_{t} k_{t}\right)^{\alpha} n_{t}^{1-\alpha}\right]^{\eta}$, as in Benhabib and Farmer (1994).

The government follows a constant money supply growth rule and injects newly created money into the economy via the lump-sum transfers to the households, $\left(M_{t}-M_{t-1}\right) / P_{t}=\int_{0}^{1} \tau_{t}(i) d i$. At any date $t$, total factor payments $w_{t} n_{t}+r_{t} u_{t} k_{t}$ and total monopolistic profits $\Pi_{t}$ exhaust the total value-added $y_{t}$, and the market-clearing condition for the final goods gives rise to a resource constraint, $y_{t}=c_{t}+k_{t+1}-\left[1-\delta\left(u_{t}\right)\right] k_{t}$. In what follows, we shall use $m_{t}, \pi_{p, t}$, and $\pi_{w, t}$ to denote real money balances, price inflation, and wage inflation, respectively.

It can be checked that there is a unique deterministic steady-state equilibrium for the economy. For local determinacy analysis, we can therefore examine a log-linearized system of equilibrium conditions around the steady state. Throughout the rest of the paper, we shall use a variable with a hat to denote the percentage deviation of that variable in level from its steady-state value.

We start with the following system that governs the log-linearized equilibrium dynamics for consumption, capital, labor, real balances, price inflation, real wage, and wage inflation,

$$
\begin{gathered}
{\left[\frac{\theta(1+\chi \epsilon)}{(1-\theta)(1-\rho \theta)}\right]\left(\widehat{\pi}_{w, t}-\rho \mathrm{E}_{\mathrm{t}} \widehat{\pi}_{w, t+1}\right)=-k_{c} \widehat{k}_{t+1}+k_{c} \widehat{k}_{t}+(1+\chi) \widehat{n}_{t}} \\
\mathrm{E}_{\mathrm{t}} \widehat{c}_{t+1}-(1-\rho)\left(\alpha \eta \tau_{k}-1\right) \widehat{k}_{t+1}-(1-\rho)(1-\alpha) \eta \tau_{n} \mathrm{E}_{\mathrm{t}} \widehat{n}_{t+1}=\widehat{c}_{t} \\
k_{c} \widehat{k}_{t+1}=-\widehat{c}_{t}+\left(k_{c}+\alpha \eta \tau_{k}\right) \widehat{k}_{t}+(1-\alpha) \eta \tau_{n} \widehat{n}_{t} \\
\rho \mathrm{E}_{\mathrm{t}} \widehat{c}_{t+1}-\rho \mathrm{E}_{\mathrm{t}} \widehat{m}_{t+1}=\widehat{c}_{t}-\widehat{m}_{t}, \\
\widehat{\pi}_{p, t}=\widehat{m}_{t-1}-\widehat{m}_{t}, \\
\widehat{w}_{t}=\alpha \eta \tau_{k} \widehat{k}_{t}+\left[(1-\alpha) \eta \tau_{n}-1\right] \widehat{n}_{t} \\
\widehat{\pi}_{w, t}=\widehat{\pi}_{p, t}+\widehat{w}_{t}-\widehat{w}_{t-1},
\end{gathered}
$$

where

$$
k_{c}=\frac{\alpha \eta(\phi-1) \rho}{(\phi \varepsilon-\alpha \eta)(1-\rho)}, \quad \tau_{k}=\frac{\phi-1}{\phi-\alpha \eta}, \quad \tau_{n}=\frac{\phi}{\phi-\alpha \eta} .
$$

Once these variables are obtained, the log-linearized equilibrium dynamics for real capital rental rate and capacity utilization rate can be determined from the log-linearized versions of (2) and (44), and then the log-linearized equilibrium dynamics of real aggregate output can be determined 
from the log-linearized version of the aggregate production function. The local stability property of the model economy can thus be obtained by analyzing the system (5)-(11). Appendices A and B contain some detail of the analysis.

\section{CALIBRATION AND INDETERMINACY RESULTS}

A challenge facing the literature of equilibrium indeterminacy and sunspot-driven business cycle fluctuations based on increasing returns to scale in production is that the required degree of increasing returns for generating indeterminacy can be implausibly large and rise quickly with the relative risk aversion in labor. One point of this paper is that unsynchronized wage adjustment can both lower the degree of increasing returns to scale required for indeterminacy to an empirically plausible level and make it invariant to the relative risk aversion in labor.

\subsection{Parameter Calibration}

One period in our model corresponds to one quarter of a physical year. We set the quarterly discount factor $\rho$ to 0.99 , which is consistent with a steady-state annualized real interest rate of 4 percent. Given this value of $\rho$, while having in mind a steady-state annual capital depreciation rate of 10 percent, we calibrate the value of $\phi$ to 1.3885 to be consistent with a steady-state quarterly capital depreciation rate of 2.6 percent in the light of the steady-state equilibrium relationship $\phi=[1-\rho(1-\delta)] /(\rho \delta) .^{2}$

To consider a value for $\chi$, the relative risk aversion in labor, we note that its inverse corresponds to the Frisch elasticity of labor supply. A large number of empirical studies have estimated the labor supply elasticity. The evidence obtained based on different sources of data, frequencies of time, sample periods, aggregation levels, substitution margins (intensive versus extensive), seasonality adjustments, and estimation procedures suggests that the elasticity lies between 0.05 and 2. Many of these studies based on life-cycle data of hours worked (intensive margin) by men at annual or lower frequencies find an elasticity in the range of 0.05 to 0.3 , as summarized by Pencavel (1986). Evidence on a low elasticity is also found by Altonji (1986), Ball (1990), and Card (1994). Using monthly data from the Denver Income Maintenance Experiment, MaCurdy (1983) finds that the

\footnotetext{
${ }^{2}$ The quarterly and annual capital depreciation rates in the steady state are related by $0.026=1-(1-0.1)^{1 / 4}$.
} 
(intensive) elasticity can be above 0.3 though it is below 0.7. Rupert, Rogerson, and Wright (2000) obtain similar estimates taking home production into account. Using tri-annual micro panel data of the Survey of Income and Program Participation, Kimmel and Kniesner (1998) estimate an hours worked elasticity (intensive margin) of 0.5 and an employment elasticity (extensive margin) of 1.5. Mulligan (1998) shows that the elasticity can lie in the 1-2 range. Many other of these studies, using multi-industry panel or macro-level data (as reported by Browning, Hansen, and Heckman, 1999), using industry-specific data (e.g., Treble, 1986; Carrington, 1996; Oettinger, 1999), and using data at several different frequencies (e.g., Abowd and Card, 1989) or taking into account seasonal variation in total hours worked (e.g., Barsky and Miron, 1989; Hall, 1999), also provide corroborating evidence that helps reach a consensus that the elasticity lies between 0.05 and 2 . This suggests a value for $\chi$ between 0.5 and 20. As we will show below, our indeterminacy result is virtually invariant to the choice of $\chi$ within a broad range.

Turning to the elasticity of substitution between differentiated labor skills, we set $\epsilon$ to 4, which is the mid point of the empirical estimates by Griffin $(1992,1996)$ that range from 2 to 6 . Our results are not sensitive to alternative values of $\epsilon$ within this empirically plausible range.

To assign a value to the hazard rate of wage adjustment $\theta$, we note that $(1-\theta)$ corresponds to the quarterly frequency of wage adjustment and the average duration of newly set wages for individual workers is given by $1 /(1-\theta)$. There is a large body of empirical work that has estimated the average length of wage setting interval, the frequency of wage adjustment, or the hazard rate. The evidence obtained based on different sources of data, sample periods, frequencies of time, aggregation levels, and estimation procedures reveals a relevant range for $\theta$ between 0.42 and 0.86 . Many studies in the 1980s and the 1990s suggest an average length of wage setting interval of about four quarters or longer for the United States and other countries, such as Canada and Sweden, based on direct microeconomic evidence on wage setting procedures and indirect estimation from macroeconomic data. Taylor (1999) contains a comprehensive survey of this literature (see also Kahn, 1997). This corresponds to a value for $\theta$ of at least 0.75 . The more recent literature is also divided into two strands, one based on macro data and the other on micro data. The macro studies typically use SDGE models to estimate the hazard rate along with other structural parameters. While the estimation of $\theta$ by Christiano, Eichenbaum, and Evans (2005) for the US ranges from 0.42 to 0.80, depending on alternative model specifications, Christiano, Motto, and Rostagno (2008) report their 
estimate of $\theta$ at 0.80 for the US and 0.83 for the Euro Area. The Bayesian estimate of $\theta$ obtained by Levin, Onatski, Williams, and Williams (2005) based on postwar US data ranges from 0.72 to 0.85. Also applying Bayesian methods, Smets and Wouters (2003) estimate $\theta$ between 0.662 and 0.824 for the Euro Area, and Smets and Wouters (2007) estimate $\theta$ between 0.60 and 0.81 for the US. DiCecio (2009) and Matheron and Poilly (2009) obtain similar estimates of $\theta$ for the US economy (0.73 and 0.775 respectively). The recent micro studies focus on estimating the frequency of wage adjustment. Using quarterly firm-level data from the Survey on Labor Activity and Employment Status (ACEMO) carried out by the French Ministry of Labor and Social Affairs for French firms over the period from 1998 to 2005, Heckel, Le Bihan, and Montornès (2008) estimate a quarterly frequency of wage adjustment of about 35 percent, implying a value for the hazard rate $\theta$ of 0.65. Analyzing data from the last two complete panels of the Survey of Income and Program Participation (SIPP) (1996-1999 and 2001-2003) run by the Bureau of Labor Statistics (BLS), Barattieri, Basu, and Gottschalk (2009) find that, in an average quarter, the probability that a representative American will experience a nominal wage change is between 14 and 16 percent, implying a value of $\theta$ between 0.84 and 0.86 . Using an administrative dataset of monthly frequency that covers all firms and employees in Luxembourg over the period between January 2001 and December 2006, and correcting for measurement errors and adjusting for institutional factors, Lunnemann and Wintr (2009) estimate a monthly frequency of wage adjustment between 5 and 7 percent, implying a quarterly frequency of wage adjustment between 14 and 19 percent. This gives rise to a range for $\theta$ between 0.81 and 0.86 . In light of the empirical evidence, we set the hazard rate of wage adjustment $\theta$ to 0.75 in the baseline model, as is standard in most theoretical studies of unsynchronized wage adjustment (e.g., Erceg, Henderson, and Levin, 2000; Rabanal and Rubio-Ramírez, 2005; Sveen and Weinke, 2007; Casares, 2010). We will also show that our results are robust to alternative values of $\theta$ within its empirically plausible range.

We here recall that the profit maximization problem has a well-defined interior solution as long as the degree of increasing returns to scale $\eta$ is bounded above by the monopolistic markup $\varepsilon$. In light of the studies by Domowitz, Hubbard, and Petersen (1986), Shapiro (1987), Basu (1996), Rotemberg (1996), Rotemberg and Woodford (1997), Basu and Fernald (1994, 1995, 1997, 2000, 2002), and Basu and Kimball (1997), a value of $\varepsilon$ between 1.05 and 1.15 can be empirically plausible. This provides a useful criterion for assessing whether the required increasing returns to scale for 
generating indeterminacy is empirically reasonable. In searching for the values of $\eta$ that produce indeterminacy, we set the two parameters $\eta$ and $\varepsilon$ equal so that profits for firms are zero. ${ }^{3}$ With zero economic profit, the parameter $\alpha$ corresponds to the share of payments to capital in total value added in the National Income and Product Account. The implied value of $\alpha$ is about 0.3 , in line with the value used in the standard business cycle literature.

Note that the two parameters $\psi_{1}$ and $\psi_{2}$ in the utility function do not affect the log-linearized equilibrium dynamics and thus we do not need to assign any particular values to them.

\subsection{Unsynchronized Wage Adjustment Reduces the Required Degree of Increasing Returns for Indeterminacy}

To appreciate the role of unsynchronized wage adjustment in reducing the required degree of increasing returns for indeterminacy, it is informative to contrast our results obtained under unsynchronized wage adjustment and under synchronized wage adjustment. Here it is useful to note that, with synchronized wage adjustment, that is, with $\theta=0$, the optimal wage-setting equation (II) and its log-linearized version (15) simplify to $w_{t}=\psi_{2} \epsilon(\epsilon-1)^{-1} c_{t} n_{t}^{\chi}$ and $0=-k_{c} \widehat{k}_{t+1}+k_{c} \widehat{k}_{t}+(1+\chi) \widehat{n}_{t}$, respectively, while all the other equilibrium conditions remain the same. This shows that our model featuring differentiated skills and monopolistic competition in the labor market with a zero hazard rate of wage adjustment is first-order equivalent to an otherwise identical model but with a homogenous skill and perfect competition in the labor market, which can be cast as an externality model such as Wen (1998) or Benhabib and Wen (2004) with money in the utility function. The comparison thus helps put into perspective our results in the light of the general literature on indeterminacy based on increasing returns to scale in production.

Table 2 reports the minimal degree of increasing returns to scale that can generate indeterminacy for the case with synchronized wage adjustment and the case with unsynchronized wage adjustment, for three values of $\chi$, the calibrated value 1 and two additional values 0.5 and 2 in its empirically plausible range. All the other parameters take on their calibrated values reported in Table 1 . The middle column of the table shows the results under synchronized wage adjustment and the three

\footnotetext{
${ }^{3}$ The equilibrium profit-output ratio in our model is equal to $1-\eta / \varepsilon$. Much empirical evidence suggests that profit rates are close to zero (e.g., Rotemberg and Woodford, 1995; Basu and Fernald, 1997). We have also experimented with the cases of positive profit rates and find that our results do not change.
} 
corresponding values of $\eta, 1.8,1.5$, and 2.3 , are all beyond its empirically plausible range [1.05, 1.15]. The right column shows the results under unsynchronized wage adjustment and the corresponding value of $\eta$ is reduced to 1.1, right in the middle of its empirically plausible range, for all the three values of $\chi$. A message from the table is thus that unsynchronized wage adjustment can lower the required degree of increasing returns for indeterminacy to an empirically plausible level.

\subsection{Unsynchronized Wage Adjustment Makes the Required Increasing Returns for Indeterminacy Invariant to the Relative Risk Aversion in Labor}

The numbers presented in Table 2 also reveal that the required degree of increasing returns for indeterminacy can rise significantly with $\chi$ under synchronized wage adjustment while it seems invariant to $\chi$ under unsynchronized wage adjustment. We find that this is true in general.

To put this contrast into perspective, Figure 1 plots the minimal value of $\eta$ that can generate indeterminacy for the case with synchronized wage adjustment and the case with unsynchronized wage adjustment for many more values of $\chi$, ranging from 0 to 20. Again, all the other parameters take on their calibrated values reported in Table 1. The broken line in the figure corresponds to the case with synchronized wage adjustment and, indeed, it increases rapidly with $\chi$ : it takes on a value of 1.1 when $\chi$ is set to 0 , quickly rises to 1.2 as $\chi$ edges up to 0.1 , and continues to increase with $\chi$ at a fast pace. The solid line corresponds to the case with unsynchronized wage adjustment and, in sharp contrast to the broken line, it stays flat at 1.1 regardless of the value of $\chi{ }^{4}$

As a further robustness check, Figure 2 plots the minimal degree of increasing returns that can generate indeterminacy as a function of the relative risk aversion in labor under synchronized wage adjustment, as well as under unsynchronized wage adjustment with three alternative hazard rates, while all other parameters take on their calibrated values. ${ }^{5}$ As can be seen from the figure, our

\footnotetext{
${ }^{4}$ Notice that the two lines in Figure 1 intercept with the vertical axis at the same point. This is so since with zero relative risk aversion in labor, households would not mind varying their labor hours even with a tiny change in wages so equilibrium wages would not change much with employment even under synchronized wage adjustment, and the effect of unsynchronized wage adjustment is muted. We have obtained an analytical result which shows that the local stability condition is the same under synchronized wage adjustment and under unsynchronized wage adjustment if $\chi$ is set to 0 . This result is available upon request from the authors.

${ }^{5}$ In our quarterly model, the benchmark calibration of the hazard rate of wage adjustment, $\theta=0.75$, implies that wages are adjusted once every four quarters on average, and a value of $\theta$ equal to 0.50 implies that wages are adjusted every other quarter on average, while as a value of $\theta$ equal to 0 implies that wages are adjusted every quarter, corresponding to the case with synchronized (and flexible) wage adjustment. While the result under $\theta=0.42$ (the lower bound on the empirical estimates of the hazard rate of wage adjustment) is very similar to that under $\theta=0.50$ (the broken line with dots in Figure 2), the result under $\theta=0.86$ (the upper bound on the empirical estimates of the hazard rate of wage adjustment) is very similar to that under $\theta=0.80$ (the broken line in Figure 2).
} 
results are robust to alternative values for the hazard rate of wage adjustment within its empirically plausible range.

Putting the above results together we conclude that, not only does unsynchronized wage adjustment lower the required degree of increasing returns for indeterminacy to an empirically plausible level, it also makes it invariant to the relative risk aversion in labor. As a consequence, an indeterminate equilibrium and thus sunspot-driven business cycle fluctuations may emerge for empirically plausible increasing returns regardless of the value of the relative risk aversion in labor.

\section{SOME INTUITION}

To understand why unsynchronized wage adjustment makes the required increasing returns to scale for indeterminacy smaller and its sensitivity to the relative risk aversion in labor disappear, we first note that the only difference between the case with synchronized wage adjustment and the case with unsynchronized wage adjustment lies in the left hands side of (5): it is zero under synchronized wage adjustment but generally nonzero under unsynchronized wage adjustment. We next recall that increasing returns to scale in production makes indeterminacy more likely to occur because it makes the optimal response of labor to a contemplated increase in capital stronger, resulting in a smaller decrease or even increase in the marginal product of capital and thus the contemplated increase in capital is more likely to be self-fulfilling. That said, with synchronized wage adjustment, a large $\chi$ serves as a counter-force to dampen the response of labor, as a large relative risk aversion in labor makes it more costly to raise labor hours under synchronized and hence flexible wage adjustment. This can be seen by imposing $\theta=0$ in (5): the response of $\widehat{n}_{t}$ to

a contemplated increase in $\widehat{k}_{t+1}$ (note that $\widehat{k}_{t}$ is predetermined) is then given by $k_{c} /(1+\chi)$, which clearly decreases with $\chi$. Thus, a large relative risk aversion in labor requires a large degree of increasing returns to start with in order to generate indeterminacy. In fact, we obtain a necessary condition for indeterminacy under synchronized wage adjustment as

$$
\eta>\frac{\phi(1+\chi)}{\alpha(1+\chi)+(1-\alpha) \phi \rho}
$$

which puts a lower bound on the required degree of increasing returns and the lower bound increases with $\chi$, manifesting our results in Section 3 for the case with synchronized wage adjustment. 
Unsynchronized wage adjustment effectively dampens the cost of raising labor hours and relieves the counter-force brought about by the relative risk aversion in labor. With unsynchronized wage adjustment, firms can optimally increase employment in response to a contemplated increase in capital without equilibrium wages rising as they would with synchronized wage adjustment. The fact that labor can be more elastic to capital if $\theta>0$ can be seen from (5): a change on the right hand side due to a large response of labor to capital can be well matched by a change on the left hand side now. To understand why $\chi$ multiplied by $\epsilon$ enters the left hand side of (5) we note that, with unsynchronized wage adjustment, even households that can adjust their wages will choose not to increase their wages much, as firms can substitute away from their more expensive labor services and toward the cheaper ones provided by other households that can't change their wages. The strength of this deterrence depends on how easy it is to substitute across the differentiated labor skills, as measured by $\epsilon$, and on how fast marginal dis-utility of working changes as hours worked fall, as determined by $\chi$. This substitution across differentiated labor skills following a relative wage change results in a small overall wage increase and a large overall employment response to the contemplated increase in capital. With labor being more elastic to capital, the marginal product of capital does not decrease as fast or even increases with capital and a self-fulfilling equilibrium is more likely to occur. The presence of $\chi$ on the left hand side of the equation via a positive $\theta$ essentially cancels out its effect on the right hand side, making the required increasing returns to scale for indeterminacy invariant to $\chi$.

To drive home our intuition in a more rigorous way, we can use (6) and (8)-(11) to solve for the wage inflation rates on the left hand side of (5) in terms of labor and capital. We consider $\eta$ in the range $\left(\rho^{-1},[\rho(1-\alpha)]^{-1}\right)$, set $\phi=\alpha \eta[1-\rho(1-\alpha) \eta]^{-1}$, and impose perfect foresight to simplify exposition. We note that $\phi$ so set is greater than $\rho^{-1}$ and the implied steady-state capital depreciation rate is strictly between 0 and 1 for any value of $\eta$ in the above range; and as $\eta$ varies across this range, $\phi$ varies from arbitrarily close to $\rho^{-1}$ to arbitrarily close to infinity. We also note that the lower end of this range for $\eta$ is close to 1 for a value of $\rho$ close to $1 .^{6}$ With some algebra, we obtain the following simplified version of (5):

$$
\left[\frac{\theta(1+\chi \epsilon)}{(1-\theta)(1-\rho \theta)}\right]\left[-k_{w} \widehat{k}_{t+1}+\widehat{q}_{t-1}+(1-\rho) \widehat{n}_{t}\right]=-k_{c} \widehat{k}_{t+1}+k_{c} \widehat{k}_{t}+(1+\chi) \widehat{n}_{t},
$$

\footnotetext{
${ }^{6}$ For example, for our calibrated values $\rho=0.99$ and $\alpha=0.3$, this range for $\eta$ is $(1.01,1.57)$.
} 
where

$$
k_{w}=\frac{\rho(\eta-1)}{(1-\alpha) \eta}
$$

and $\widehat{q}_{t-1}$ is predetermined and is given by

$$
\widehat{q}_{t-1}=\left[\frac{1}{\rho}-1-\frac{\eta-1}{\rho(1-\alpha) \eta}\right] \widehat{k}_{t-1}+\left[\frac{2(\eta-1)}{(1-\alpha) \eta}-1+\rho\right] \widehat{k}_{t}+\left(1-\frac{1}{\rho}\right) \widehat{n}_{t-1} .
$$

Equation (12) helps make our intuition more transparent. Since $k_{w}$ increases with $\eta$ and $\rho<1$, unsynchronized wage adjustment makes given existing returns more effective in generating an elastic response of labor to a contemplated increase in capital, as a change on the right hand side of (12) can be matched by a change on the left hand side due to a large increase in labor, and the response is no longer sensitive to $\chi$, as its effects on both sides of the equation are essentially canceled out.

\section{COMPUTING SUNSPOTS EQUILIBRIA}

To gain further insight into the dynamic properties of the model, we study the model's general solution and impulse responses to various shocks. We consider two fundamental shocks as in Benhabib and Wen (2004), a preference shock and a government spending shock. As in Wen (1998) and Benhabib and Wen (2004), period utility derived from date-t consumption is now specified as $\log \left(c_{t}-\mu_{t}\right)$, where $\mu_{t}$ is a shock to consumption that generates the urge to consume. We also consider as in Benhabib and Wen (2004) a shock to government spending, $g_{t}$, representing a pure resource drain from the economy. The government budget constraint in period $t$ is now specified

as $\left(M_{t}-M_{t-1}\right) / P_{t}=\int_{0}^{1} \tau_{t}(i) d i+g_{t}$, and the resource constraint for period $t$ is now given by $y_{t}=c_{t}+k_{t+1}-\left[1-\delta\left(u_{t}\right)\right] k_{t}+g_{t}$. We postulate stationary $\mathrm{AR}(1)$ log-normal processes for the fundamental shocks,

$$
\begin{aligned}
& \log \left(\mu_{t}\right)=\left(1-\rho_{\mu}\right) \log (\mu)+\rho_{\mu} \log \left(\mu_{t-1}\right)+\varepsilon_{\mu t}, \quad \varepsilon_{\mu t} \rightarrow i . i . d .\left(0, \sigma_{\mu}^{2}\right), \\
& \log \left(g_{t}\right)=\left(1-\rho_{g}\right) \log (g)+\rho_{g} \log \left(g_{t-1}\right)+\varepsilon_{g t}, \quad \varepsilon_{g t} \rightarrow \text { i.i.d. }\left(0, \sigma_{g}^{2}\right) .
\end{aligned}
$$

The log-linearized equilibrium system is then given by

$$
\gamma\left(\widehat{\pi}_{w, t}-\rho \mathrm{E}_{\mathrm{t}} \widehat{\pi}_{w, t+1}\right)=\mu_{c} \widehat{c}_{t}+\chi \widehat{n}_{t}-\widehat{w}_{t}+\left(1-\mu_{c}\right) \widehat{\mu}_{t},
$$




$$
\begin{gathered}
\mu_{c} \mathrm{E}_{\mathrm{t}} \widehat{c}_{t+1}-(1-\rho)\left(\alpha \eta \tau_{k}-1\right) \widehat{k}_{t+1}-(1-\rho)(1-\alpha) \eta \tau_{n} \mathrm{E}_{\mathrm{t}} \widehat{n}_{t+1}=\mu_{c} \widehat{c}_{t}+\left(1-\mu_{c}\right)\left(1-\rho_{\mu}\right) \widehat{\mu}_{t}, \\
k_{c} \widehat{k}_{t+1}=-\left(1-g_{y}\right) \widehat{c}_{t}+\left(k_{c}+\alpha \eta \tau_{k}\right) \widehat{k}_{t}+(1-\alpha) \eta \tau_{n} \widehat{n}_{t}-g_{y} \widehat{g}_{t}, \\
\mu_{c} \widehat{c}_{t}-\rho \mu_{c} \mathrm{E}_{\mathrm{t}} \widehat{c}_{t+1}+\left(1-\mu_{c}\right)\left(1-\rho \rho_{\mu}\right) \widehat{\mu}_{t}=(1-\rho) \widehat{m}_{t}+\rho \mathrm{E}_{\mathrm{t}} \widehat{\pi}_{p, t+1}, \\
\widehat{\pi}_{p, t}=\widehat{m}_{t-1}-\widehat{m}_{t}, \\
\widehat{w}_{t}=\alpha \eta \tau_{k} \widehat{k}_{t}+\left[(1-\alpha) \eta \tau_{n}-1\right] \widehat{n}_{t}, \\
\widehat{\pi}_{w, t}=\widehat{\pi}_{p, t}+\widehat{w}_{t}-\widehat{w}_{t-1}, \\
\widehat{y}_{t}=\widehat{w}_{t}+\widehat{n}_{t}, \\
\widehat{i}_{t}=\frac{\rho(\phi-1)}{1-\rho}\left(\widehat{k}_{t+1}-\widehat{k}_{t}\right)+\widehat{y}_{t}, \\
\phi \widehat{u}_{t}=\widehat{y}_{t}-\widehat{k}_{t}, \\
\widehat{\mu}_{t}=\rho_{\mu} \widehat{\mu}_{t-1}+\varepsilon_{\mu t}, \\
\widehat{g}_{t}=\rho_{g} \widehat{g}_{t-1}+\varepsilon_{g t},
\end{gathered}
$$

where

$$
\gamma=\frac{\theta(1+\chi \epsilon)}{(1-\theta)(1-\rho \theta)}, \quad \mu_{c}=\frac{1}{1-\mu / c}, \quad g_{y}=\frac{\phi \varepsilon}{\phi \varepsilon-\alpha \eta} \frac{g}{y}
$$

and we have invoked the condition that $\mathrm{E}_{\mathrm{t}} \widehat{k}_{t+1}=\widehat{k}_{t+1}$, since capital at date $t+1$ is known at date $t$ so the one-period forecast error on capital is zero, and that $\mathrm{E}_{t} \widehat{\mu}_{t+1}=\rho_{\mu} \widehat{\mu}_{t}$ and $\mathrm{E}_{\mathrm{t}} \widehat{g}_{t+1}=\rho_{g} \widehat{g}_{t}$, since agents know the probability distributions of the fundamental shocks so the forecast errors on these shocks are equal to the true disturbances.

We will use an algorithm proposed by Sims (2002), Lubik and Schorfheide (2003), and Hespeler (2008a,b) to solve the log-linearized equilibrium system. To this end, we introduce endogenous forecast errors $\eta_{t}^{c}, \eta_{t}^{n}, \eta_{t}^{\pi_{w}}$, and $\eta_{t}^{\pi_{p}}$ as $\eta_{t}^{c}=\widehat{c}_{t}-\mathrm{E}_{\mathrm{t}-1} \widehat{c}_{t}, \eta_{t}^{n}=\widehat{n}_{t}-\mathrm{E}_{\mathrm{t}-1} \widehat{n}_{t}, \eta_{t}^{\pi_{w}}=\widehat{\pi}_{w, t}-\mathrm{E}_{\mathrm{t}-1} \widehat{\pi}_{w, t}$, and $\eta_{t}^{\pi_{p}}=\widehat{\pi}_{p, t}-\mathrm{E}_{\mathrm{t}-1} \widehat{\pi}_{p, t}$, and we denote $\xi_{t}^{c}=\mathrm{E}_{\mathrm{t}} \widehat{c}_{t+1}, \xi_{t}^{n}=\mathrm{E}_{\mathrm{t}} \widehat{n}_{t+1}, \xi_{t}^{\pi_{w}}=\mathrm{E}_{\mathrm{t}} \widehat{\pi}_{w, t+1}$, and $\xi_{t}^{\pi_{p}}=\mathrm{E}_{\mathrm{t}} \widehat{\pi}_{p, t+1}$. The system can then be represented by

$$
\Gamma_{0} x_{t}=\Gamma_{1} x_{t-1}+\Psi \varepsilon_{t}+\Pi \eta_{t}
$$


where

$$
\begin{aligned}
& x_{t}=\left[\begin{array}{llllllllllllllll}
\widehat{y}_{t} & \widehat{c}_{t} & \widehat{n}_{t} & \hat{i}_{t} & \widehat{k}_{t+1} & \widehat{\pi}_{w, t} & \widehat{\pi}_{p, t} & \widehat{w}_{t} & \widehat{m}_{t} & \widehat{u}_{t} & \xi_{t}^{c} & \xi_{t}^{n} & \xi_{t}^{\pi_{w}} & \xi_{t}^{\pi_{p}} & \widehat{\mu}_{t} & \left.\widehat{g}_{t}\right]^{\prime},
\end{array}\right. \\
& \varepsilon_{t}=\left[\begin{array}{ll}
\varepsilon_{\mu t} & \varepsilon_{g t}
\end{array}\right]^{\prime}, \quad \eta_{t}=\left[\begin{array}{llll}
\eta_{t}^{c} & \eta_{t}^{n} & \eta_{t}^{\pi_{w}} & \eta_{t}^{\pi_{p}}
\end{array}\right]^{\prime}
\end{aligned}
$$

and the two $16 \times 16$ matrices, $\Gamma_{0}$ and $\Gamma_{1}$, the $16 \times 2$ matrix, $\Psi$, and the $16 \times 4$ matrix, $\Pi$, are as specified in Appendix C. The system can be transformed (and sorted and partitioned) through a generalized complex Schur decomposition of $\Gamma_{0}$ and $\Gamma_{1}$ by four $16 \times 16$ matrices, $Q, Z, \Lambda$, and $\Omega$, with $\Lambda$ and $\Omega$ being upper triangular, $Q^{\prime} \Lambda Z^{\prime}=\Gamma_{0}, Q^{\prime} \Omega Z^{\prime}=\Gamma_{1}$, and $Q Q^{\prime}=Z Z^{\prime}=I$, into a system of 16 equations about transformed variables $\omega_{t}=Z^{\prime} x_{t}$,

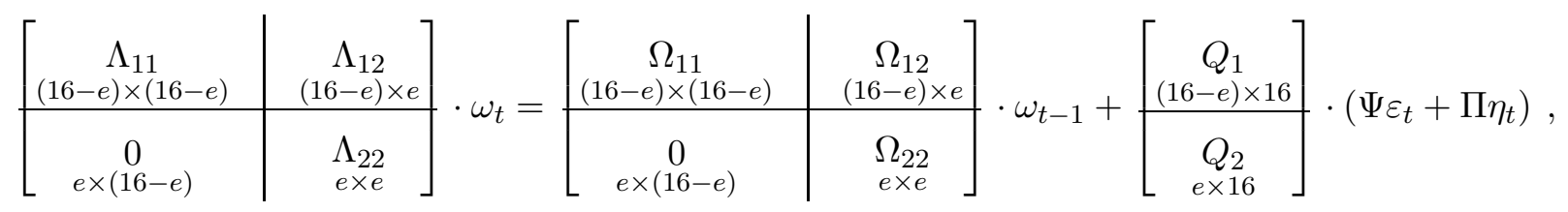

in which the last $e \in[0,16]$ equations are explosive and the first $(16-e)$ equations are stable. Since the rows of the $e \times 4$ matrix $Q_{2} \Pi$ are potentially linearly dependent, its singular value decomposition can generally be expressed as

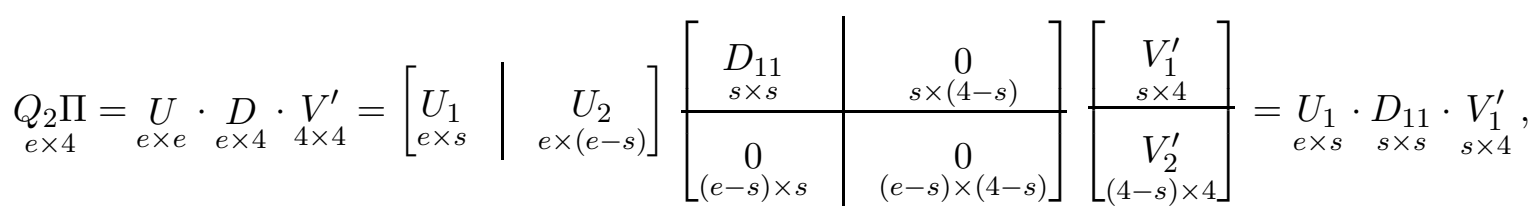

where $D_{11}$ is an invertible, diagonal matrix, and $U$ and $V$ are orthonormal matrices.

When the degree of returns to scale is smaller than 1.1, we have $e=s=4$, and the system has a unique equilibrium in which the expectations errors $\eta_{t}$ are uniquely determined by the fundamental shocks $\varepsilon_{t}$,

$$
\eta_{t}=-V_{1} D_{11}^{-1} U_{1}^{\prime} Q_{2} \Psi \varepsilon_{t}
$$

and the solution satisfies

$$
\Gamma_{0} x_{t}=\Gamma_{1} x_{t-1}+\left(I-\Pi V_{1} D_{11}^{-1} U_{1}^{\prime} Q_{2}\right) \Psi \varepsilon_{t} .
$$


Decompose $Z$ into $Z=\left[\begin{array}{cc}Z_{1} & Z_{2}\end{array}\right]$, the unique solution under determinacy is given by

$$
\begin{array}{cl}
x_{t}= & Z_{1} \Lambda_{11}^{-1}\left\{\Omega_{11} Z_{1}^{\prime}+\left[\Omega_{12}-Q_{1} \Pi\left(Q_{2} \Pi\right)^{+} \Omega_{22}\right] Z_{2}^{\prime}\right\} x_{t-1} \\
+ & Z_{1} \Lambda_{11}^{-1}\left[Q_{1}-Q_{1} \Pi\left(Q_{2} \Pi\right)^{+} Q_{2}\right] \Psi \varepsilon_{t},
\end{array}
$$

where $\left(Q_{2} \Pi\right)^{+}$is the right-side pseudoinverse of $Q_{2} \Pi$.

When the degree of returns to scale is greater than 1.1, we have $e=s=3$, and the system has a one-dimensional indeterminacy so there is room for sunspots to affect the forecast errors $\eta_{t}$ and other endogenous variables. We consider here a one-dimensional reduced-form i.i.d. sunspot shock, $\zeta_{t} \rightarrow$ i.i.d. $\left(0, \sigma_{\zeta}^{2}\right){ }^{7}$ Under indeterminacy, the forecast errors $\eta_{t}$ can be influenced by both the fundamental shocks $\varepsilon_{t}$ and the sunspot shock $\zeta_{t}$,

$$
\eta_{t}=\left(-V_{1} D_{11}^{-1} U_{1}^{\prime} Q_{2} \Psi+V_{2} A\right) \varepsilon_{t}+V_{2} \zeta_{t}
$$

and the full set of solutions is characterized by

$$
\Gamma_{0} x_{t}=\Gamma_{1} x_{t-1}+\left[\left(I-\Pi V_{1} D_{11}^{-1} U_{1}^{\prime} Q_{2}\right) \Psi+\Pi V_{2} A\right] \varepsilon_{t}+\Pi V_{2} \zeta_{t}
$$

where $A$ is an arbitrary $1 \times 2$ matrix. Decompose $Z$ into $Z=\left[\begin{array}{cc}Z_{1} & Z_{2}\end{array}\right]$, the full set of solutions under indeterminacy is given by

$$
\begin{aligned}
x_{t}= & Z_{1} \Lambda_{11}^{-1}\left[\Omega_{11} Z_{1}^{\prime}+\left(\Omega_{12}-\Lambda_{12} \Omega_{22}\right) Z_{2}^{\prime}\right] x_{t-1} \\
+ & Z_{1} \Lambda_{11}^{-1}\left(Q_{1}-\Lambda_{12} Q_{2}\right)\left[\left(I-\Pi V_{1} D_{11}^{-1} U_{1}^{\prime} Q_{2}\right) \Psi+\Pi V_{2} A\right] \varepsilon_{t} \\
+ & Z_{1} \Lambda_{11}^{-1}\left(Q_{1}-\Lambda_{12} Q_{2}\right) \Pi V_{2} \zeta_{t} .
\end{aligned}
$$

To put into perspective our model's dynamics in the light of those obtained by Benhabib and Wen (2004) and Wen (1998), we invoke the same values of parameters as in these papers when solving our model numerically, except for the two parameters pertaining to the labor market frictions, the elasticity of substitution of differentiated labor skills, $\epsilon$, and the hazard rate of wage

\footnotetext{
${ }^{7}$ In the case of indeterminacy, multiple sunspot shocks may influence equilibrium dynamics so the effect of sunspots is not uniquely determined. The reduced-form sunspot shock that we have considered here should be regarded as a linear combination of multiple sunspot shocks with no restriction on the weight assigned to each individual component.
} 
adjustment, $\theta$, which are unique to our model, and which we set to 4 and 0.75 , respectively, as reported in Table $1 .{ }^{8}$ This allows us to examine the effect of these labor market frictions on equilibrium dynamics when compared to Benhabib and Wen (2004) and Wen (1998). Also, we choose the steady-state values of $\mu_{t}$ and $g_{t}$ such that $\mu / c=0.1$ and $g / y=0.2$ in the steady state, and we set $\rho_{\mu}=\rho_{g}=0.9$ and $\sigma_{\mu}=\sigma_{g}=\sigma_{\zeta}=1$, while innovations in fundamentals are assumed to be orthogonal to each other and to sunspots, as in Benhabib and Wen (2004).

To illustrate the effect of indeterminacy on equilibrium dynamics, we present the impulse responses of the model to the fundamental shocks under determinacy, and to both the fundamental shocks and the sunspot shock under indeterminacy. Specifically, we examine two versions of our model, one with the degree of returns to scale equal to 1.1 (the case of determinacy), and the other with the degree of returns to scale equal to 1.11 (the case of indeterminacy), as in Benhabib and Wen (2004) and Wen (1998). When considering the impulse responses to one type of shocks, we turn off the other type(s) of shocks by setting the corresponding variance(s) to zero. Also, when considering the impulse responses to a consumption shock, we set the steady-state government spending-to-output ratio $g / y$ to zero; likewise, when considering the impulse responses to a government spending shock, we set the steady-state ratio $\mu / c$ to zero; and, when considering the impulse responses to a sunspot shock under indeterminacy, we set the two steady-state ratios $g / y$ and $\mu / c$ both to zero. This is the same procedure followed by Benhabib and Wen (2004) when examining their model's impulse responses to the various shocks.

Figure 3 displays the impulse responses of output, consumption, investment, and hours worked under determinacy (e.g., $\eta=1.1$ ). The solid lines are responses to a positive one-standard-deviation consumption shock and the broken lines are responses to a positive one-standard-deviation government spending shock. These responses are similar to those obtained in Benhabib and Wen (2004) under determinacy: both show positive comovements among output, consumption, investment, and hours worked, with the amplitude of response in investment bigger than those in output and hours worked, which are bigger than that in consumption, as seen from the data; but, output responses in both cases are monotone, as opposed to the hump-shaped initial output responses seen in the data (e.g., Wen, 1998). The magnitudes of responses are greater here than in Benhabib and Wen (2004), particularly for output, investment, and hours worked, manifesting the propagation mechanism

\footnotetext{
${ }^{8}$ Our results are robust to alternative values of these two parameters within their empirically plausible ranges.
} 
embodied in the labor market frictions.

Figure 4 plots the impulse responses of output, consumption, investment, and hours worked under indeterminacy (e.g., $\eta=1.11$ ). The solid lines are responses to a positive one-standard-deviation consumption shock, the broken lines are responses to a positive one-standard-deviation government spending shock, and the broken lines with dots are responses to a one-standard-deviation sunspot shock that leads to an upward revision in forecast errors. ${ }^{9}$ These responses are similar to those obtained in Benhabib and Wen (2004) under indeterminacy: in addition to quantity comovements and relative volatility, persistent cycles emerge following demand shocks (except for consumption's response to a consumption shock), including an i.i.d. sunspot shock, and initial output responses to serially correlated demand shocks are significantly hump-shaped. The magnitudes of responses to a sunspot shock are much greater here than in Benhabib and Wen (2004), indicating that the labor market frictions hold a key for the significance of the model's response to sunspot shocks.

In sum, while the impulse responses of the model to demand shocks under indeterminacy are as reasonable as those in Benhabib and Wen (2004) in terms of matching the business cycle as shown by Wen (1998), sunspot shocks seem much more important here than in Benhabib and Wen (2004) due to the presence of labor market frictions.

\section{CONCLUDING REMARK}

We have studied the role of labor market frictions in the form of unsynchronized wage adjustment in inducing indeterminacy and sunspot-driven business cycles. Our finding is that unsynchronized wage adjustment both lowers the required degree of increasing returns for indeterminacy to an empirically plausible level and makes it invariant to the relative risk aversion in labor. In consequence, indeterminacy and sunspot-driven business cycle fluctuations can emerge for empirically plausible increasing returns regardless of the value of the relative risk aversion in labor. We have shown that indeterminacy holds the key for the propagation mechanism of the model. In particular, the model's impulse responses to demand shocks under indeterminacy are reasonable in terms of matching the business cycle, while sunspot shocks seem to become a more important source of business cycle fluctuations in the face of labor market frictions.

\footnotetext{
${ }^{9}$ In generating the impulse responses to fundamental shocks under indeterminacy, we set $A=0_{1 \times 2}$. Varying $A$ can vary the amplitude of the model's impulse responses to fundamental shocks under indeterminacy, corresponding to various equilibria, but not much other cyclical property of the impulse responses.
} 


\section{APPENDIX A: ANALYSIS WITH SYNCHRONIZED WAGE ADJUSTMENT}

We show that the stability property of the system (5)-(11) for the case with synchronized wage adjustment can be obtained by analyzing a three-equation system. We first note that, with $\theta=0$, (5)-(8) constitute a self-closed system for consumption, capital, labor, and real balances. Once these variables are obtained, price inflation can be determined from (91), real wage from (10), and then wage inflation from (11). We next notice that (7) implies that (51) with $\theta=0$ can be rewritten as $\widehat{c}_{t}-\alpha \eta \tau_{k} \widehat{k}_{t}+\left[1+\chi-(1-\alpha) \eta \tau_{n}\right] \widehat{n}_{t}=0$. We can then use this relation to substitute out labor from (6) and (7), which together with (8) constitute a self-closed three-equation system in consumption, capital, and real balances,

$$
\begin{gathered}
{\left[\frac{1+\chi-\rho(1-\alpha) \eta \tau_{n}}{1+\chi-(1-\alpha) \eta \tau_{n}}\right] \mathrm{E}_{\mathrm{t}} \widehat{c}_{t+1}+(1-\rho)\left[1-\frac{\alpha \eta(1+\chi) \tau_{k}}{1+\chi-(1-\alpha) \eta \tau_{n}}\right] \widehat{k}_{t+1}=\widehat{c}_{t},} \\
k_{c} \widehat{k}_{t+1}=-\left[\frac{1+\chi}{1+\chi-(1-\alpha) \eta \tau_{n}}\right] \widehat{c}_{t}+\left[k_{c}+\frac{\alpha \eta(1+\chi) \tau_{k}}{1+\chi-(1-\alpha) \eta \tau_{n}}\right] \widehat{k}_{t} \\
\rho \mathrm{E}_{\mathrm{t}} \widehat{c}_{t+1}-\rho \mathrm{E}_{\mathrm{t}} \widehat{m}_{t+1}=\widehat{c}_{t}-\widehat{m}_{t} .
\end{gathered}
$$

Since this system contains one predetermined variable (capital) and two jump variables (consumption and real balances), indeterminacy requires at least two eigenvalues lying inside the unit circle.

\section{APPENDIX B: ANALYSIS WITH UNSYNCHRONIZED WAGE ADJUSTMENT}

We show that the stability property of the system (15)-(11) for the case with unsynchronized wage adjustment can be obtained by analyzing a six-equation system. We first use (77) to substitute out $k_{t+1}$ from the right hand side of (5), we then use (10) to substitute out labor from (6) and (17), and we next use (9)-(11) to substitute out labor and wage inflation from (5). We arrive at the following system consisting of six equations,

$$
\begin{aligned}
& \rho \mathrm{E}_{\mathrm{t}} \widehat{m}_{t+1}-\rho \mathrm{E}_{\mathrm{t}} \widehat{w}_{t+1} \\
&= \gamma^{-1} \widehat{c}_{t}+\left[\frac{\gamma^{-1} \chi \alpha \eta \tau_{k}}{1-(1-\alpha) \eta \tau_{n}}\right] \widehat{k}_{t}+(1+\rho) \widehat{m}_{t}-\widehat{s}_{t}-\left[1+\rho+\gamma^{-1} \frac{1+\chi-(1-\alpha) \eta \tau_{n}}{1-(1-\alpha) \eta \tau_{n}}\right] \widehat{w}_{t}+\widehat{z}_{t}, \\
& \mathrm{E}_{\mathrm{t}} \widehat{c}_{t+1}+(1-\rho)\left[1-\frac{\alpha \eta \tau_{k}}{1-(1-\alpha) \eta \tau_{n}}\right] \widehat{k}_{t+1}+\left[\frac{(1-\rho)(1-\alpha) \eta \tau_{n}}{1-(1-\alpha) \eta \tau_{n}}\right] \mathrm{E}_{\mathrm{t}} \widehat{w}_{t+1}=\widehat{c}_{t},
\end{aligned}
$$




$$
\begin{gathered}
k_{c} \widehat{k}_{t+1}=-\widehat{c}_{t}+\left[k_{c}+\frac{\alpha \eta \tau_{k}}{1-(1-\alpha) \eta \tau_{n}}\right] \widehat{k}_{t}-\left[\frac{(1-\alpha) \eta \tau_{n}}{1-(1-\alpha) \eta \tau_{n}}\right] \widehat{w}_{t} \\
\rho \mathrm{E}_{\mathrm{t}} \widehat{c}_{t+1}-\rho \mathrm{E}_{\mathrm{t}} \widehat{m}_{t+1}=\widehat{c}_{t}-\widehat{m}_{t} \\
\widehat{s}_{t+1}=\widehat{m}_{t}, \\
\widehat{z}_{t+1}=\widehat{w}_{t}
\end{gathered}
$$

where $\widehat{k}_{t}, \widehat{s}_{t}, \widehat{z}_{t}$ are predetermined variables, and $\widehat{c}_{t}, \widehat{m}_{t}$, and $\widehat{w}_{t}$ are jump variables, so indeterminacy requires at least four eigenvalues lying inside the unit circle.

\section{APPENDIX C: COMPUTING SUNSPOTS EQUILIBRIA}

The four matrices in Equation (25) are defined as follows:

$$
\Gamma_{0}=\left[\begin{array}{cccccccccccccccc}
0 & 0 & 0 & 0 & 0 & 0 & 0 & 1 & 0 & 0 & 0 & 0 & -\gamma \rho & 0 & \mu_{c}-1 & 0 \\
0 & 0 & 0 & 0 & \frac{\alpha \eta \tau_{k}-1}{(\rho-1)^{-1}} & 0 & 0 & 0 & 0 & 0 & \mu_{c} & \frac{(1-\alpha) \eta \tau_{n}}{(\rho-1)^{-1}} & 0 & 0 & \frac{1-\rho_{\mu}}{\left(\mu_{c}-1\right)^{-1}} & 0 \\
0 & 0 & 0 & 0 & k_{c} & 0 & 0 & 0 & 0 & 0 & 0 & 0 & 0 & 0 & 0 & g_{y} \\
0 & 0 & 0 & 0 & 0 & 0 & 0 & 0 & 1-\rho & 0 & \rho \mu_{c} & 0 & 0 & \rho & \frac{1-\rho \rho_{\mu}}{\left(\mu_{c}-1\right)^{-1}} & 0 \\
0 & 0 & 0 & 0 & 0 & 0 & 0 & 0 & 1 & 0 & 0 & 0 & 0 & 0 & 0 & 0 \\
0 & 0 & 0 & 0 & 0 & 0 & 0 & 1 & 0 & 0 & 0 & 0 & 0 & 0 & 0 & 0 \\
0 & 0 & 0 & 0 & 0 & 0 & 0 & 1 & 0 & 0 & 0 & 0 & 0 & 0 & 0 & 0 \\
1 & 0 & 0 & 0 & 0 & 0 & 0 & -1 & 0 & 0 & 0 & 0 & 0 & 0 & 0 & 0 \\
1 & 0 & 0 & -1 & \frac{\rho(\phi-1)}{1-\rho} & 0 & 0 & 0 & 0 & 0 & 0 & 0 & 0 & 0 & 0 & 0 \\
1 & 0 & 0 & 0 & 0 & 0 & 0 & 0 & 0 & -\phi & 0 & 0 & 0 & 0 & 0 & 0 \\
0 & 1 & 0 & 0 & 0 & 0 & 0 & 0 & 0 & 0 & 0 & 0 & 0 & 0 & 0 & 0 \\
0 & 0 & 1 & 0 & 0 & 0 & 0 & 0 & 0 & 0 & 0 & 0 & 0 & 0 & 0 & 0 \\
0 & 0 & 0 & 0 & 0 & 1 & 0 & 0 & 0 & 0 & 0 & 0 & 0 & 0 & 0 & 0 \\
0 & 0 & 0 & 0 & 0 & 0 & 1 & 0 & 0 & 0 & 0 & 0 & 0 & 0 & 0 & 0 \\
0 & 0 & 0 & 0 & 0 & 0 & 0 & 0 & 0 & 0 & 0 & 0 & 0 & 0 & 1 & 0 \\
0 & 0 & 0 & 0 & 0 & 0 & 0 & 0 & 0 & 0 & 0 & 0 & 0 & 0 & 0 & 1
\end{array}\right]
$$




$\Gamma_{1}=\left[\begin{array}{cccccccccccccccc}0 & 0 & 0 & 0 & 0 & 0 & 0 & 0 & 0 & 0 & \mu_{c} & \chi & -\gamma & 0 & 0 & 0 \\ 0 & 0 & 0 & 0 & 0 & 0 & 0 & 0 & 0 & 0 & \mu_{c} & 0 & 0 & 0 & 0 & 0 \\ 0 & 0 & 0 & 0 & k_{c}+\alpha \eta \tau_{k} & 0 & 0 & 0 & 0 & 0 & g_{y}-1 & (1-\alpha) \eta \tau_{n} & 0 & 0 & 0 & 0 \\ 0 & 0 & 0 & 0 & 0 & 0 & 0 & 0 & 0 & 0 & \mu_{c} & 0 & 0 & 0 & 0 & 0 \\ 0 & 0 & 0 & 0 & 0 & 0 & 0 & 0 & 1 & 0 & 0 & 0 & 0 & -1 & 0 & 0 \\ 0 & 0 & 0 & 0 & \alpha \eta \tau_{k} & 0 & 0 & 0 & 0 & 0 & 0 & (1-\alpha) \eta \tau_{n}-1 & 0 & 0 & 0 & 0 \\ 0 & 0 & 0 & 0 & 0 & 0 & 0 & 1 & 0 & 0 & 0 & 0 & 1 & -1 & 0 & 0 \\ 0 & 0 & 0 & 0 & 0 & 0 & 0 & 0 & 0 & 0 & 0 & 1 & 0 & 0 & 0 & 0 \\ 0 & 0 & 0 & 0 & \frac{\rho(\phi-1)}{1-\rho} & 0 & 0 & 0 & 0 & 0 & 0 & 0 & 0 & 0 & 0 & 0 \\ 0 & 0 & 0 & 0 & 1 & 0 & 0 & 0 & 0 & 0 & 0 & 0 & 0 & 0 & 0 & 0 \\ 0 & 0 & 0 & 0 & 0 & 0 & 0 & 0 & 0 & 0 & 1 & 0 & 0 & 0 & 0 & 0 \\ 0 & 0 & 0 & 0 & 0 & 0 & 0 & 0 & 0 & 0 & 0 & 1 & 0 & 0 & 0 & 0 \\ 0 & 0 & 0 & 0 & 0 & 0 & 0 & 0 & 0 & 0 & 0 & 0 & 1 & 0 & 0 & 0 \\ 0 & 0 & 0 & 0 & 0 & 0 & 0 & 0 & 0 & 0 & 0 & 0 & 0 & 1 & 0 & 0 \\ 0 & 0 & 0 & 0 & 0 & 0 & 0 & 0 & 0 & 0 & 0 & 0 & 0 & 0 & \rho_{\mu} & 0 \\ 0 & 0 & 0 & 0 & 0 & 0 & 0 & 0 & 0 & 0 & 0 & 0 & 0 & 0 & 0 & \rho_{g}\end{array}\right]$




$\Psi=\left[\begin{array}{ll}0 & 0 \\ 0 & 0 \\ 0 & 0 \\ 0 & 0 \\ 0 & 0 \\ 0 & 0 \\ 0 & 0 \\ 0 & 0 \\ 0 & 0 \\ 0 & 0 \\ 0 & 0 \\ 0 & 0 \\ 0 & 0 \\ 0 & 0 \\ 1 & 0 \\ 0 & 1\end{array}\right], \quad\left[\begin{array}{cccc}\mu_{c} & \chi & -\gamma & 0 \\ \mu_{c} & 0 & 0 & 0 \\ g_{y}-1 & (1-\alpha) \eta \tau_{n} & 0 & 0 \\ \mu_{c} & 0 & 0 & 0 \\ 0 & 0 & 0 & -1 \\ 0 & (1-\alpha) \eta \tau_{n}-1 & 0 & 0 \\ 0 & 0 & 1 & -1 \\ 0 & 1 & 0 & 0 \\ 0 & 0 & 0 & 0 \\ 0 & 0 & 0 & 0 \\ 1 & 0 & 0 & 0 \\ 0 & 1 & 0 & 0 \\ 0 & 0 & 1 & 0 \\ 0 & 0 & 0 & 1 \\ 0 & 0 & 0 & 0 \\ 0 & 0 & 0 & 0\end{array}\right]$

\section{ACKNOWLEDGMENTS}

We are grateful to an associate editor and a referee for very useful comments and suggestions, which have helped improve the paper substantially.

\section{REFERENCES}

Abowd, J.M., Card, D., 1989. On the covariance structure of earnings and hours changes. Econometrica 57, 411-445.

Altonji, J.G., 1986. Intertemporal substitution in labor supply: evidence from micro data. Journal of Political Economy 94, S176-S215.

Ball, L., 1990. Intertemporal substitution and constraints on labor supply: evidence from panel data. Economic Inquiry 28, 706-724. 
Barattieri, A., Basu, S., Gottschalk, P., 2009. Some evidence on the importance of sticky wages. Manuscript, Boston College.

Barsky, R.B., Miron, J.A., 1989. The seasonal cycle and the business cycle. Journal of Political Economy 97, 503-534.

Basu, S., 1996. Procyclical productivity: increasing returns or cyclical utilization? Quarterly Journal of Economics 111, 719-751.

Basu, S., Fernald, J.G., 1994. Constant returns and small markups in U.S. manufacturing. International Finance Discussion Paper 483, Board of Governors of the Federal Reserve System.

Basu, S., Fernald, J.G., 1995. Are apparent productive spillovers a figment of specification error? Journal of Monetary Economics 36, 165-188.

Basu, S., Fernald, J.G., 1997. Returns to scale in U.S. production: estimates and implications. Journal of Political Economy 105, 249-283.

Basu, S., Fernald, J.G., 2000. Why is productivity procyclical? Why do we care? NBER Working Paper 7940.

Basu, S., Fernald, J.G., 2002. Aggregate productivity and aggregate technology. European Economic Review 46, 963-991.

Basu, S., Kimball, M.S., 1997. Cyclical productivity with unobserved input variation. NBER Working Paper 5915.

Benhabib, J., Farmer, R.E.A., 1994. Indeterminacy and increasing returns. Journal of Economic Theory $63,19-41$.

Benhabib, J., Farmer, R.E.A., 1996. Indeterminacy and sector-specific externalities. Journal of Monetary Economics 37, 421-443.

Benhabib, J., Wen, Y., 2004. Indeterminacy, aggregate demand, and the real business cycle. Journal of Monetary Economics 51, 503-530.

Browning, M., Hansen, L.P., Heckman, J.J., 1999. Micro data and general equilibrium models. Handbook of Macroeconomics, Vol. 1A. Elsevier Science Publishers, Amsterdam.

Calvo, G., 1983. Staggered prices in a utility maximizing framework. Journal of Monetary Economics 12, 383-398.

Card, D., 1994. Intertemporal labor supply: an assessment. In: Sims, C. (ed.), Advances in Econometrics. Cambridge University Press, New York. 
Carrington, W.J., 1996. The Alaskan labor market during the pipeline era. Journal of Political Economy 104, 186-218.

Casares, M., 2010. Unemployment as excess supply of labor: Implications for wage and price inflation. Journal of Monetary Economics, in press.

Christiano, L.J., Eichenbaum, M., Evans, C., 2005. Nominal rigidities and the dynamic effects of a shock to monetary policy. Journal of Political Economy 113, 1-45.

Christiano, L.J., Motto, R., Rostagno, M., 2008. Shocks, structures or monetary policies? The Euro Area and US after 2001. Journal of Economic Dynamics and Control 32, 2476-2506.

DiCecio, R., 2009. Sticky wages and sectoral labor comovement. Journal of Economic Dynamics and Control 33, 538-553.

Domowitz, I.R., Hubbard, G., Petersen, B.C., 1986. Business cycles and the relationship between concentration and price-cost margins. Rand Journal of Economics 17, 1-17.

Erceg, C.J., Henderson, D.W., Levin, A.T., 2000. Optimal monetary policy with staggered wage and price contracts. Journal of Monetary Economics 46, 281-313.

Greenwood, J., Hercowitz, Z., Huffman, G.W., 1988. Investment, capacity utilization, and the real business cycle. American Economic Review 78, 402-417.

Griffin, P., 1992. The impact of affirmative action on labor demand: a test of some implications of the Le Chatelier principle. Review of Economics and Statistics 74, 251-260.

Griffin, P., 1996. Input demand elasticities for heterogeneous labor: firm-level estimates and an investigation into the effects of aggregation. Southern Economic Journal 62, 889-901.

Hall, R.E., 1999. Labor-market frictions and employment fluctuations. In: Taylor, J.B., Woodford, M. (eds.), Handbook of Macroeconomics Vol. 1B. Elsevier Science, Amsterdam.

Heckel, T., Le Bihan, H., Montornès, J., 2008. Sticky wages: Evidence from quarterly microeconomic data. ECB Working Paper Series No. 893.

Hespeler, F., 2008a. Solution algorithm to a class of monetary rational equilibrium macromodels with optimal monetary policy design. Computational Economics 31, 207-223.

Hespeler, F., 2008b. A correction of misstated equations in Hespeler (2008). Computational Economics, 32, 341-342.

Kahn, S., 1997. Evidence of nominal wage stickiness from microdata. American Economic Review 87, 993-1008. 
Kimmel, J., Kniesner, T.J., 1998. New evidence on labor supply: employment versus hours elasticities by sex and marital status. Journal of Monetary Economics 42, 289-302.

Levin, A.T., Onatski, A., Williams, J.C., Williams, N., 2005. Monetary policy under uncertainty in micro-founded macroeconometric models. In: Gertler, M., Rogoff, K. (eds.), NBER Macroeconomic Annual. MIT Press, Cambridge.

Lunnemann, P., Wintr, L., 2009. Wage are flexible, aren't they? Evidence from monthly micro wage data. ECB Working Paper Series No. 1074.

Lubik, T.A., Schorfheide, F., 2003. Computing sunspot equilibria in linear rational expectations models. Journal of Economic Dynamics and Control 28, 273-285.

Macurdy, T.E., 1983. A simple scheme for estimating an intertemporal model of labor supply and consumption in the presence of taxes and uncertainty. International Economic Review 24, 265-289.

Matheron, J., Poilly, C., 2009. How well does a small structural model with sticky prices and wages fit postwar U.S. data? Economic Modeling 26, 266-284.

Mulligan, C.B., 1999. Substitution over time: another look at life cycle labor supply. In: Bernanke, B.S., Rotemberg, J.J. (eds.), NBER Macroeconomics Annual. MIT Press, Cambridge.

Oettinger, G.S., 1999. Am empirical analysis of the daily labor supply of stadium vendors. Journal of Political Economy 107, 360-392.

Pencavel, J., 1986. The labor supply of men: a survey. In: Ashenfelter, O.C., Richard, L. (eds.), Handbook of Labor Economics, Vol. 1. North-Holland, Amsterdam.

Rabanal, P., Rubio-Ramírez, J.F., 2005. Comparing New Keynesian models of the business cycle: A Baysian approach. Journal of Monetary Economics 52, 1151-1166.

Rotemberg, J.J., 1996. Prices, output and hours: an empirical analysis based on a sticky price model. Journal of Monetary Economics 37, 505-533.

Rotemberg, J.J., Woodford, M., 1995. Dynamic general equilibrium models with imperfectly competitive product markets. In: Cooley, T.F. (ed.), Frontier of Business Cycle Research. Princeton University Press, New Jersey.

Rotemberg, J.J., Woodford, M., 1997. An optimization-based econometric framework for the evaluation of monetary policy. In: Bernanke, B.S., Rotemberg, J.J. (eds.), NBER Macroeconomics Annual. MIT Press, Cambridge. 
Rupert, P., Rogerson, R., Wright, R., 2000. Homework in labor economics: household production and intertemporal substitution. Journal of Monetary Economics 46, 557-579.

Shapiro, M.D., 1987. Measuring market power in U.S. industry. NBER Working Paper 2212.

Sims, C.A., 2002. Solving linear rational expectations models. Computational Economics 20, 1-20.

Smets, F., Wouters, R., 2003. An estimated dynamic stochastic general equilibrium model of the euro area. Journal of the European Economic Association 1, 1123-1175.

Smets, F., Wouters, R., 2007. Shocks and frictions in US business cycles: A Bayesian DSGE approach. American Economic Review 97, 586-606.

Sveen, T., Weinke, L., 2007. Firm-specific capital, nominal rigidities, and the Taylor principle. Journal of Economic Theory 136, 729-737.

Taylor, J.B., 1999. Staggered price and wage setting in macroeconomics. In: Taylor, J.B., Woodford, M. (eds.), Handbook of Macroeconomics Vol. 1B. North Holland, Amsterdam.

Treble, J.G., 1986. Intertemporal substitution of effort: some empirical evidence. Unpublished manuscript.

Wen, Y., 1998. Capacity utilization under increasing returns to scale. Journal of Economic Theory $81,7-36$. 
Table 1-Parameter Calibration

\begin{tabular}{lc}
\hline \hline Parameters & Values \\
\hline Subjective quarterly discount factor $(\rho)$ & 0.99 \\
Curvature parameter in the capital depreciation function $(\phi)$ & 1.3885 \\
Elasticity of substitution of differentiated labor skills $(\epsilon)$ & 4 \\
Hazard rate of wage adjustment $(\theta)$ & 0.75 \\
Share of payments to capital in total value added $(\alpha)$ & 0.3 \\
\hline \hline
\end{tabular}

Table 2-Minimal Degree of Increasing Returns to Scale That Can Generate Indeterminacy

\begin{tabular}{ccc}
\hline \hline & Synchronized wage adjustment & Unsynchronized wage adjustment \\
\hline Relative risk aversion in labor & & \\
$\chi=0.5$ & 1.5 & 1.1 \\
$\chi=1^{\star}$ & 1.8 & 1.1 \\
$\chi=2$ & 2.3 & 1.1 \\
\hline \hline
\end{tabular}

Note: The value of $\chi$ denoted by $\star$ in the first column of the table is the baseline calibration for $\chi$. All other parameters take on their calibrated values. 


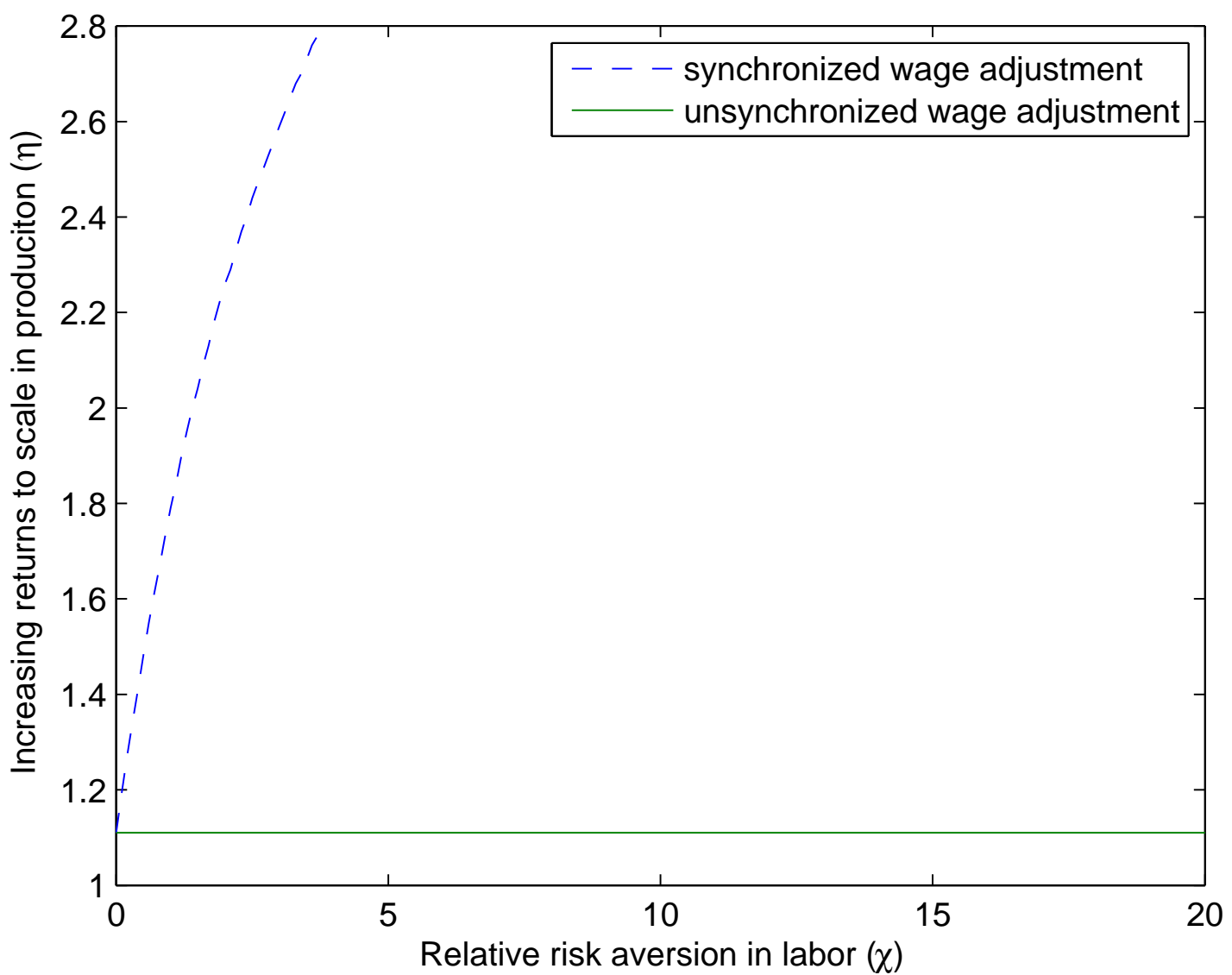

Figure 1. Minimal degree of increasing returns to scale that can generate indeterminacy as a function of the relative risk aversion in labor (all other parameters take on their calibrated values) 


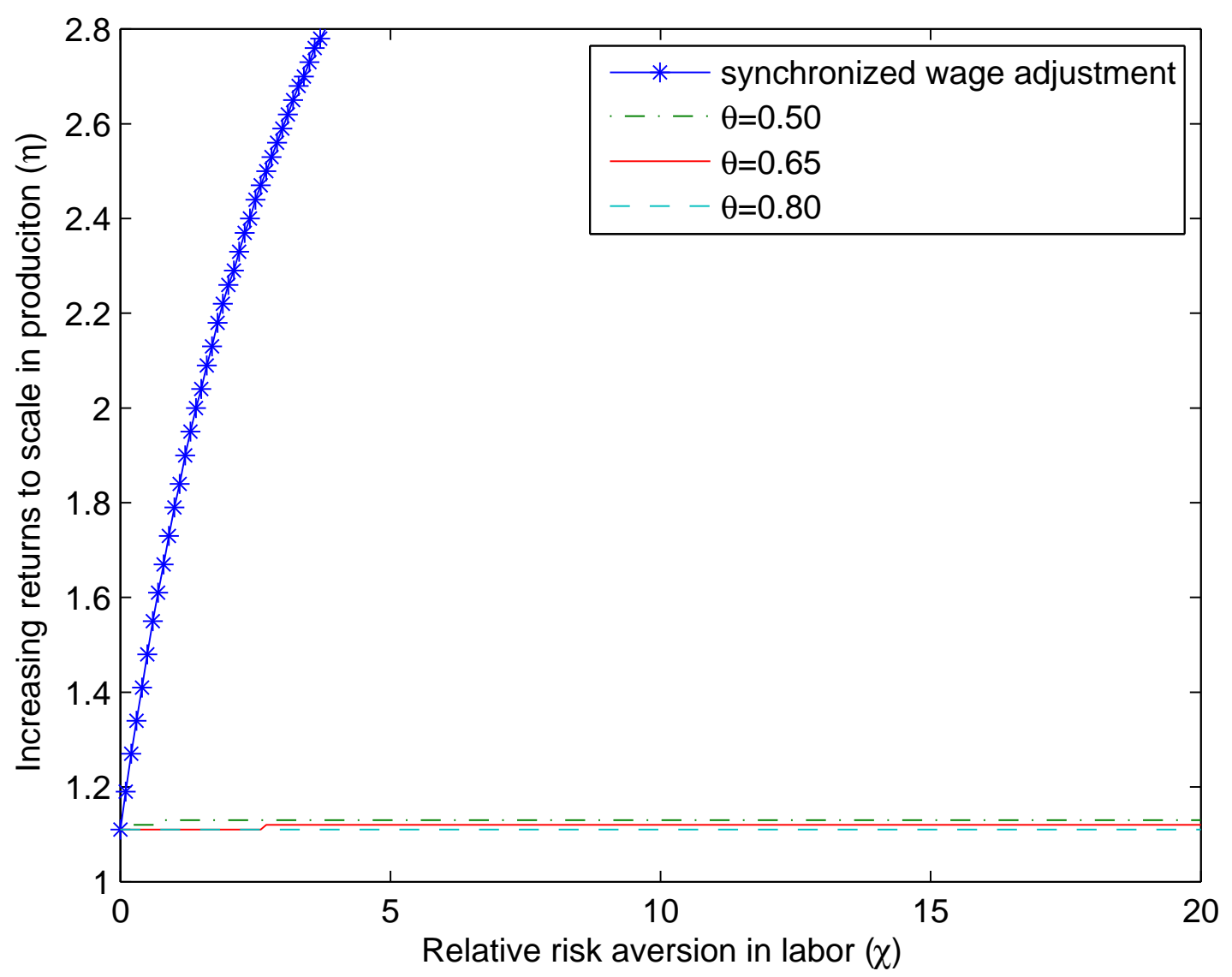

Figure 2. Minimal degree of increasing returns to scale that can generate indeterminacy as a function of the relative risk aversion in labor (with three alternative hazard rates for unsynchronized wage adjustment while all other parameters take on their calibrated values) 

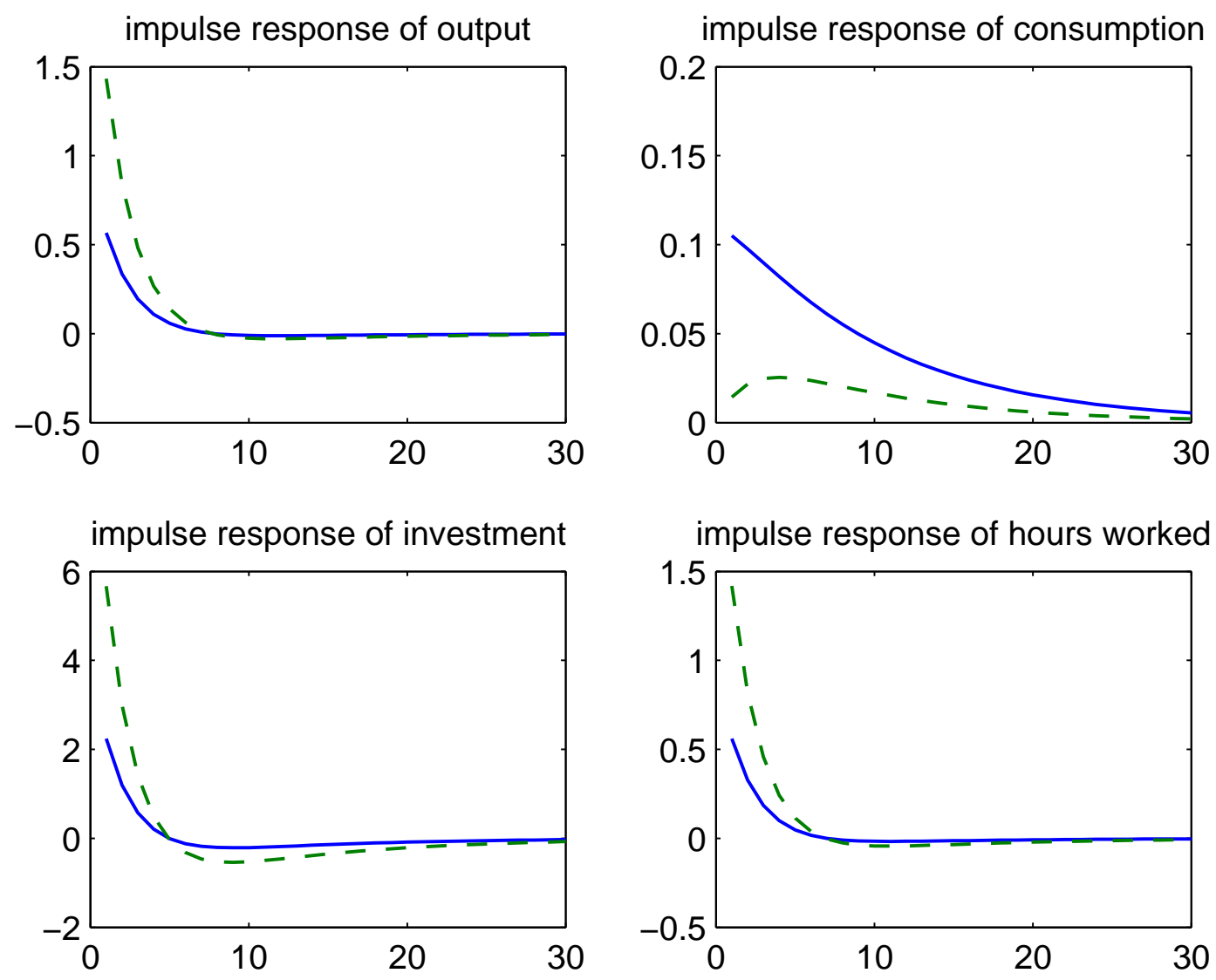

Figure 3. Impulse responses of output, consumption, investment, and hours worked under determinacy $(\eta=1.1)$. The solid lines are responses to a consumption shock and the broken lines are responses to a government spending shock 

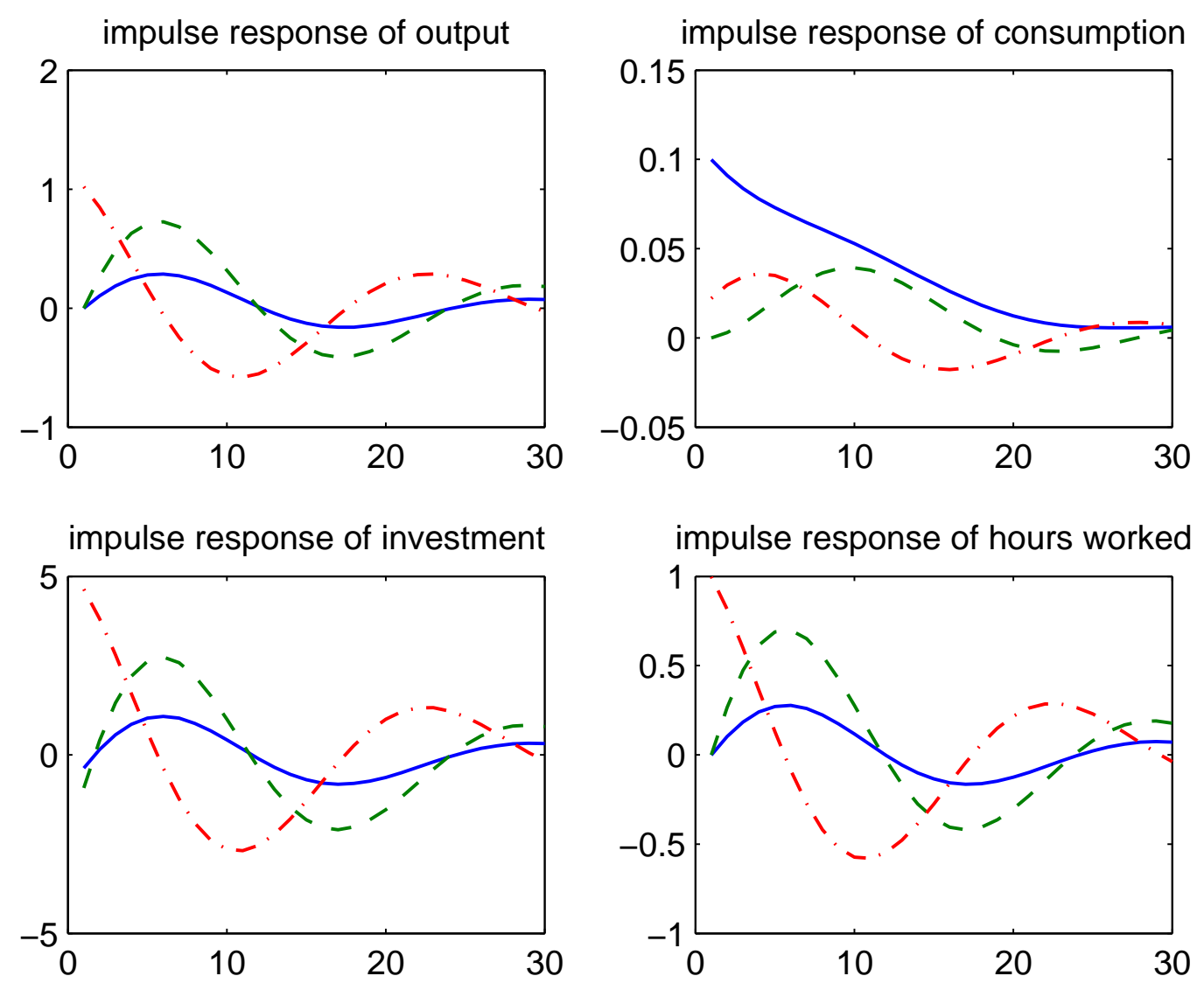

Figure 4. Impulse responses of output, consumption, investment, and hours worked under indeterminacy $(\eta=1.11)$. The solid lines are responses to a consumption shock, the broken lines are responses to a government spending shock, and the broken lines with dots are responses to a sunspot shock 